remark is in a way the keynote of the book and, indeed, of Prof. Piaget's work generally. Every remark or action of the child, even his first 'mummy' or 'bow-wow', is worthy of the most painstaking examination. It is on the analysis of the same material that Prof. Piaget has erected his imposing axiomatic system as described in his recent "Introduction à l'Épistemologie Génétique" (1950), an English translation of which is very much to be desired since it would provide the necessary stimulus for a wider discussion of this important work.

The translators of the present work deserve commendation for their excellent performance, which has won much praise from the author himself.

JoHN COHEN

\section{THE PRACTICE OF SCIENTIFIC RESEARCH}

An Introduction to Scientific Research

By Prof. E. Bright Wilson, Jr. Pp. xiii +375 . (London: McGraw-Hill Publishing Co., Ltd., 1952.) $51 s$.

THE title of Prof. E. Bright Wilson's book might suggest one of those works which, though they often stimulate discussion, have not been known to influence any actual research. On the contrary, the present book mainly comprises practical advice. After a short chapter more or loss about why a scientist undertakes research, the second chapter gives some elements of the technique of an information service, that is, how to find, assemble and store the essentials of relevant prior work. The next chapter, on scientific method, is somewhat metaphysical; but it is sensible, not profound. The chapter on the design of experiments goes into more detail on subjects such as replication, factorial analysis and significance; but it tends to be discursive with brief common-sense observations on a number of topics which have a general connexion with how an experiment is approached. Under the headings of the design of apparatus and the execution of experiments, the author treats the elements of laboratory and workshop practice in scientific work. There are useful suggestions and interesting information; but the mixture is uneven, for the range of topics includes aphorisms about taking records and accessibility in the design of apparatus needing maintenance, fundamental matters such as the limitation of sensitivity by random fluctuation, and technological subjects such as closed control and amplifying systems.

The next four chapters, taking up nearly half the book, comprise a more systematic treatment of statistical principles and techniques, particularly for the assessment of significance. Some topies are included, such as confidence limits and quality control, which are of use more often in industrial studies. On the other hand, there is some formal logic at the beginning of the section, and it closes with the logical basis of probability theory, mentioning symbolic logic in passing. The author clearly attaches great importance to the assessment of the probability that a scientific conclusion is valid, and he explains what he means with care. The last three chapters return to the discursive style of the opening, with one or two notes on mathematical processes, a brief survey of modern aids to computation and hints on writing reports and papers.
The value of a book of this kind depends upon a judicious selection and treatment in the light of the needs of an important enough class of reader. It will not appeal to the experienced man of science, because it is too elementary and because there are too many important omissions in its lists of sources. Indeed, some remarks are so elementary that the student who needed to be told them would seem ill-advised to attempt a scientific career. Nevertheless, we must not forget that the vast expansion in scientific pursuits means that a great and increasing number of young scientific workers will lack the opportunity of acquiring a general knowledge of scientific endeavour and an appreciation of the realities of scientific research by direct contact with leading men of science. To those so placed, this book can be of value. They will realize that the life's work of a man of great ability and industry may be enshrined in a single sentence in a text-book. They will understand that, although a young scientist's research problem may seem very specialized, yet if he is to make a real advance he may have to call on a surprisingly wide range of knowledge and skill. This book can save the young scientific worker much unrewarding toil and inspire him to broaden his studies truly to fit himself for his calling.

$$
\text { S. WhITEHEAD }
$$

\section{A TEXT-BOOK OF PRACTICAL BOTANY}

\section{Textbook of Practical Botany}

By Prof. R. C. McLean and Dr. W. R. Ivimey-Cook. Pp. xxiv +476 . (London, New York and Toronto: Longmans, Green and Co., Itd., 1952.) 36s. net.

$T$ $\mathrm{HE}$ authors justify the appearance of this work, a companion volume to their "Textbook of Theoretical Botany", by pointing to the scarcity of practical text-books. It is written for "a general University course", which presumably means General B.Sc. standard, and how far such a book is needed at this stage is controversial. Ideally, at this level, the student should treat each exercise as an independent investigation, and in the main obtain the guidance he needs from standard works. By so doing he will learn his way about the literature and, at the same time, acquire a healthy independence of outlook. To work by this method alone would call for much more time than is normally available.

At the other extreme the student can be issued with schedules and instructions for all his practical work, but such 'cookery book' botany is far from ideal. In practice, some half-way measure seems to be indicated, and this is a part which the present book could fill. Very detailed instructions over the wide field which it covers are clearly out of the question in a book of fewer than five hundred pages, and there has been a good deal of careful selection so that parts of the syllabus which are not likely to be done in practical are omitted. Some of the sections are very short-variation (four pages), evidences for evolution (two pages), hybridization and inheritance (eight pages) and plant ecology, including snil analysis (nineteen pages). The student therefore could scarcely rely on this book alone, and more references to suitable literature might have been desirable. How far the book maintains a good balance must, of course, be a matter of opinion, and it would be unfair 